\title{
Exploring the Extent and Determinants of Knowledge Sharing in Audit Engagements
}

\author{
Chee W. Chow ${ }^{\mathrm{a}}$, Joanna L. Ho ${ }^{\mathrm{b} *}$, and Sandra C. Vera-Muñoz \\ ${ }^{a}$ San Diego State University \\ ${ }^{b}$ University of California, Irvine \\ ${ }^{c}$ University of Notre Dame
}

\begin{abstract}
Audit firms are faced with increasing demands for audit efficiency and effectiveness. Increasing knowledge sharing in audit engagements can help them respond to this challenge, and this study seeks to advance understanding of the extent and determinants of such sharing. Data collected from auditors of two Big Four audit firms suggest that both firms have high, but far from complete, levels of knowledge sharing. The factors identified as affecting such sharing range from characteristics of the client to attributes of the audit firm, audit team and individual auditors. A framework is proposed for organizing these factors and relationships.
\end{abstract}

JEL Classification: M42

Keywords: Audit efficiency, audit effectiveness, knowledge sharing

\section{Introduction and Overview}

Knowledge is increasingly being viewed as a key source of competitive advantage, economic growth, and corporate value, with many large global corporations having launched formal initiatives to promote knowledge sharing among employees (e.g. Dow Chemical, Hewlett-Packard, Shell, Xerox). This widespread attention to knowledge sharing is based on the belief that bringing together the full range of employees' skills, knowledge, and experience increases the effectiveness with which firms can solve problems, avoid repeating mistakes and spread the adoption of best practices (Collins and Smith, 2006; Robinson et al., 2006; Weick, 2005).

Just as knowledge sharing among employees can increase organizational effectiveness, it can enhance the effectiveness, efficiency and integrity of the audit process in formulating the most appropriate audit opinion (Vera-Muñoz et al., 2006;

\footnotetext{
* Corresponding author: Joanna L. Ho, Merage School of Business, University of California, Irvine, CA 92697. Tel: (949) 824-4041. Fax: (949) 725-2833. Email: jlho@uci.edu. We are indebted to the auditors of two Big Four firms who participated in this study.
} 
Umemoto et al., 2004). Improvements along these dimensions are critical to the survival and success of accounting firms, as the nature of the audit market has dramatically changed after the demise of Arthur Andersen and the enactment of new requirements for audit quality and attestation scope (e.g. the Sarbanes-Oxley Act of 2002; the Public Accounting Oversight Board's Auditing Standard No. 2). Complying with these new regulations has vastly increased audit costs, in turn intensifying pressures for increasing audit effectiveness and efficiency. ${ }^{1}$

In the specific case of audit engagements, individual members of the audit team typically perform only a discrete part of the audit process, such that knowledge about the client environment, industry, and interactions with the client's operations is unevenly distributed among members of the audit team (Murthy and Kerr, 2004; Harding and Trotman, 1999). Compounding this uneven distribution of knowledge, audit firms are increasingly adopting a more holistic "top down" methodology-based on obtaining an in-depth understanding of clients' business strategies and processes (e.g. Bell et al., 2005). This shift in practice has caused auditors to focus more on audit evidence related to management actions, the quality of processes and internal controls in the broadest sense. These types of evidence are generally "softer" than the documentary evidence that auditors have traditionally relied on to conduct an audit, ${ }^{2}$ making knowledge sharing within an audit engagement even more important to obtaining a desired level of assurance that clients' financial statements are free of material misstatements.

Based on a review of studies in accounting, organizational learning, psychology, and knowledge management, Vera-Muñoz et al. (2006) have inferred a variety of factors that may affect individual auditors' sharing or seeking of knowledge. However, they stop short of empirically testing whether these factors do indeed affect knowledge sharing in audit engagements and to our knowledge, no published study has reported such a systematic empirical undertaking. The objective of this study is to contribute initial evidence on the topic and to develop a potential framework for organizing the relevant factors and their interrelationships. Consistent with the exploratory nature of this investigation, we used semi-structured interviews and a survey to seek the views of experienced auditors from all ranks at two Big Four accounting firms.

The remainder of this paper is organized as follows. The next section briefly discusses a range of factors that may affect the openness of knowledge sharing in audit engagements. Then in Section 3, we describe the instrument and data collection method.

\footnotetext{
${ }^{1}$ For example, Deloitte \& Touche reports that large business firms have spent, on average, nearly 70,000 additional man-hours to comply with the Sarbanes-Oxley Act of 2002 (Special Report, 2005, p.71). In dollar terms, a survey of 217 public companies by Financial Executives International (FEI) found that these companies had paid, on average, year-one compliance costs of \$4.36 million in 2005. This survey also found that Sarbanes-Oxley attestation fees as a percentage of audit fees have increased substantially since January 2004. Across all respondents, increases in attestation fees were estimated to be $37.7 \%$ in January 2004, but actually reached 57.1\% in March 2005 (The Controller's Report, 2005).

${ }^{2}$ Thus, for example, Knechel (2000, p.706) has argued that “[a]uditors often 'know' more about clients than traditional audit methods recognize, including knowledge of the quality of people, processes, and business plans. Although this knowledge is rarely documented and often difficult to link to specific assertions or audit risks, it is nevertheless vital for conducting an efficient and effective audit."
} 
Section 4 presents our findings. The final section proposes a framework for organizing the findings and discusses potential directions for practice and future research.

\section{Some Potential Determinants of Knowledge Sharing in Audit Engagements}

Extant accounting research has reported findings that knowledge sharing in organizations can be affected by various factors. For example, studies have found that a major motivation for knowledge hoarding (the converse of sharing) is to influence the performance evaluation process (e.g. Chow et al., 1991). However, whether these findings can be applied to audit settings may be open to question, as they have mostly focused on generic or general management contexts. Below, we briefly discuss a number of factors that may affect knowledge sharing in audit engagements, starting with ones at the macro level (e.g. the audit firm), and progressing to ones at more micro levels (e.g. the audit team and individual auditors). This review is partly based on Vera-Muñoz et al. (2006), though we also bring in factors that they did not consider. The objective is not to provide an exhaustive list of potentially relevant factors. Rather, the aim is to establish a sufficient structure for guiding interpretation and organization of the findings.

\subsection{Factors at the Audit Firm Level}

\subsubsection{Organizational Culture}

An organization's culture can be conceived as comprising the written and unwritten norms, values, beliefs, and daily practices that shape the aspirations and actions of organizational participants, including their patterns of communication (Cyert and March, 1992; Henri, 2006). Research in accounting shows that organizational culture can affect the motivation, behavior and performance of accounting firm personnel generally (e.g. Bhimani, 2003; Chow et al., 2002), as well as specific decisions and actions such as auditor judgment on materiality (Carpenter et al., 1994) and auditor independence (Windsor and Ashkanasy, 1996). Field-based studies and practitioners have suggested that organizational culture can also inhibit or enable knowledge sharing (Chow et al., 1999b, 2000; Stimpson, 1999). Vera-Muñoz et al. (2006) argue that while these findings and observations were not directed at accounting firms or audit engagements per se, they do provide a basis for expecting that the more a firm's cultural norms encourage knowledge hoarding as a source of power or job security, the more its auditors would withhold what they know from other members of their audit team.

\subsubsection{Performance Evaluation and Reward System}

A major determinant of organizational culture is how the firm evaluates and rewards employees (e.g. Matsumura and Shin, 2006; Fisher et al., 2005). Both the business press (e.g. Hickins, 1999) and academic studies (e.g. Chow et al., 1991) report that a firm's performance evaluation and reward system can significantly affect the extent and truthfulness of subordinates' communications to superiors. As suggested by Vera-Muñoz et al. (2006), this literature has not directly addressed the impact on knowledge sharing in an audit. However, it does provide a reasonable basis for expecting that performance 
evaluation would affect individual auditors' propensity to share knowledge in audit engagements.

\subsubsection{Use of Information Technology}

All of the Big Four accounting firms have engaged information technology for codifying and sharing knowledge among their personnel. These applications include decision support and expert systems, database management, Internet, Intranet, best practice studies, surveys, statistics, expert knowledge for specific problems, and pointto-point knowledge (i.e. information from previous client work shared by auditors) (Banker et al., 2002; Winograd et al., 2000). ${ }^{3}$ But as Vera-Muñoz et al. (2006) have argued, the existence of an expert knowledge system does not per se automatically guarantee effective knowledge sharing. In part, this is because cost considerations and the unraveling nature of audits make it unlikely that the system's coverage can be allinclusive. But even if the coverage is complete, individual auditors still need to sort through the available codified knowledge and to exercise judgment about which pieces are applicable to the situation at hand.

\subsubsection{Structure of Audit Approach}

Audit approach structure refers to the extent to which organizational activities are formalized, standardized and holistically integrated (Bowrin, 1998; Bamber et al., 1989). Prior research on audit structure has paid only limited attention to its effect on knowledge sharing, and the results to date are mixed. Some researchers suggest that the constraints of a high audit structure reduce the frequency of interactions among individual audit team members, as well as the types and amounts of information exchanged in those interactions (e.g. Bamber et al., 1989). Others argue, in contrast, that a structured audit approach benefits communication by coordinating and controlling information flows (e.g. Cushing and Loebbecke, 1986), though a structured audit approach can also cause information overload, or the exchange of greater quantities of information than individuals can efficiently use (Rudolph and Welker, 1998). In addition, prior research has suggested other avenues whereby a structured audit approach may affect knowledge sharing. For example, Francis (1994) found that the loss of professional autonomy associated with structured audit approaches increased turnover among senior audit staff and, by implication, loss of the knowledge imbued in the departed personnel. Kinney (1986) examined the relation between audit firm structure and the staff to partner ratio. He found that highly structured audit firms had fewer audit staff per partner than less structured firms. Thus, the degree of structure in the audit approach may influence the ratio of staff time to partner time and through that, the extensiveness and/or nature of interactions among audit team members. Taken as a whole, these prior studies provide a reasonable basis for expecting that the degree of structure in a firm's audit approach would affect knowledge sharing in audit engagements, though whether the net impact is an increase or decrease is an open question.

\footnotetext{
${ }^{3}$ Examples include KPMG Peat Marwick's Kworld ${ }^{\mathrm{TM}}$, PricewaterhouseCooper's TeamAsset ${ }^{\mathrm{TM}}$ and KnowledgeCurve ${ }^{\mathrm{TM}}$, and Ernst \& Young's KnowledgeWeb ${ }^{\mathrm{TM}}$.
} 


\subsubsection{Personnel Turnover}

All accounting firms experience personnel turnover, and a number of studies have examined the relationship between this factor and such outcomes as organizational identification (e.g. Bamber and Iyer, 2002) and organizational commitment (e.g. Ketchand and Strawser, 2001). Organizational commitment, in turn, can affect the effectiveness of communications within the organization (Putti et al., 1990). More closely related to the performance of an audit, Geiger and Raghunandan (2002) report that auditor tenure significantly affects audit report quality. In total, these prior studies provide a reasonable basis for expecting that auditor turnover would dampen knowledge sharing in an audit. For example, a lower level of organizational identification or commitment could reduce auditors' tendency to mentor others, or to share knowledge that can improve the efficiency or effectiveness of audit procedures.

\subsection{Factors at the Audit Team Level}

\subsubsection{Time and Workload Pressure}

Time constraints and workload pressure are present in virtually all audit engagements (Gramling, 1999; Public Oversight Board, 1994). Such constraints can reduce efforts at knowledge sharing. For example, in a survey of 100 leading UK companies (KPMG, 2000 ), $49 \%$ of the respondents said that people want to share knowledge but do not have the time to do so.

In the course of an audit, if members of the audit team perceive that they are faced with a high level of workload pressure, then they may give efficiency considerations priority over other concerns. For example, audit seniors may respond to workload pressure by allowing little or no time for providing feedback to audit staff (Bierstaker and Wright, 2001). Audit team members may also curtail their knowledge sharing out of concern that it may raise further questions or requests for follow-on procedures (McNair, 1991; Raghunathan, 1991). Overall, these findings suggest that workload pressure may degrade both the extent and quality of knowledge sharing among audit team members (Vera-Muñoz et al., 2006; Rudolph and Welker, 1998).

\subsubsection{Supervision and Feedback}

Auditing standards have long required the provision of supervision for audit team members, and the AICPA has further promulgated principles of supervision, which in turn are used by audit firms as the basis for developing more detailed practices. Supervision typically connotes downward communication in the form of advice about task-related matters, such as task instructions, objectives, suggestions, assessments of plans and the results of past decisions (Hall, 1996). If the communication of these kinds of information is deficient, then audit team members may be ill-equipped to resolve important issues concerning how to perform tasks and interpret audit information (Rudolph and Welker, 1998). Brazel et al. (2004) report that as compared with the electronic review, a face-to-face review makes preparers feel more accountable, more concerned with audit effectiveness and produce higher quality judgments. Vera-Muñoz et al. (2006) posit that close supervision increases supervisors' understanding of the 
challenges being faced by subordinates. More frequent communication between audit team leaders and members also can reduce the latter's role conflict and ambiguity, thus stimulating more, and more focused, proactive transmissions of knowledge. ${ }^{4}$ In addition, subordinates are more likely to develop trust in superiors with whom they have a close working relationship, and this may reduce their reluctance to seek advice or reveal unfavorable findings. Finally, a close working relationship can facilitate transfer of knowledge through an apprenticeship-like relationship between supervisor and subordinate.

\subsection{Factors at the Auditor Level}

\subsubsection{Rank}

Prior research has reported that accounting firms' performance evaluation, compensation and promotion systems emphasize different factors across ranks (Abdolmohammadi and Shanteau, 1992). At the audit staff (assistant) level, auditors with superior performance evaluations are distinguished by their technical knowledge. For audit seniors, tasks requiring managerial knowledge begin to enter their performance evaluation process to a small extent. At the manager and partner levels, allocating and managing human resources become critical responsibilities. Concurrently, activities like communicating and sharing knowledge with other members of the audit team (e.g. through training and supervision of subordinates) also increase in importance for their performance evaluation and promotion (Tan and Libby, 1997). Furthermore, perceptions of the work environment may differ across auditor ranks (Chow et al., 2002), which also could affect judgments about knowledge that is available or useful to share. The combination of job responsibilities and knowledge base suggests that the openness of knowledge sharing would increase with auditor rank.

\subsubsection{Individual Characteristics}

Empirical studies have reported numerous systematic differences among individual auditors. Examples include ability and motivation (e.g. Bonner and Walker, 1994); role conflict (e.g. Gregson et al., 1994); and locus of control (e.g. Hyatt and Prawitt, 2001). Because most of the interactions among audit team members occur within the review process, many of the systematic differences between auditors come into play in this process. For example, Ramsay (1994) and Harding and Trotman (1999) provide evidence of between-reviewer variance attributable to knowledge differences. It seems likely that at least some of these auditor characteristics would affect the openness with which knowledge is shared in conducting the audit.

\footnotetext{
${ }^{4}$ Vera-Muñoz et al. (2006) explain that role conflict occurs when different groups or persons with whom an individual must interact (e.g. supervisors, co-workers, subordinates, clients) hold conflicting expectations about that individual's behavior. Role ambiguity refers to uncertainty on the part of employees about key requirements of their jobs.
} 


\subsection{Summary}

As the preceding discussion has illustrated, both the context and determinants of knowledge sharing in an audit engagement can be quite complex. Not only are there multiple factors at each level, but there also may exist interactions within factors at the same level as well as across levels. For example, each audit team member's tendency to hoard knowledge may depend on his or her organizational identification and commitment, which is likely to be affected by the firm's reward system and level of personnel turnover and rotation. While it is feasible to infer from the extant literature yet other potentially relevant variables and relationships, empirical verification of these inferences' validity is needed at some point. Below, we turn to a discussion of how we collected data for this purpose.

\section{Method}

\subsection{Questionnaire Development, Content, and Administration}

We used semi-structured interviews and a survey to collect data from experienced auditors. ${ }^{5}$ The instrument contained both closed- and open-ended questions. Participants were first asked to rate the overall level of knowledge sharing typically attained in their firm's audits in general, and in each of the three stages of the audit in particular (i.e. planning, fieldwork and opinion formulation). The 100-point response scale was anchored at the low end by $0=$ "totally incomplete and closed", and at the high end by $100=$ "totally complete and open". Participants were also asked to assign 100 points among the three audit stages to reflect the relative importance of knowledge sharing in each stage to formulating the most appropriate overall audit opinion. To permit a limited set of quantitative tests (discussed further below), closed-ended questions were included about the extent to which there was workload pressure, the closeness of supervision of audit staff and the respondents' work experience. Then open-ended questions focused on eliciting examples of the typical ways in which knowledge is not shared in each audit stage, common barriers to knowledge sharing and examples of actions that the respondents' firms can take to encourage knowledge sharing.

Several features of the instrument design were aimed at reducing threats to the findings' validity. First, since the instrument asked participants to recall past experiences, this could have induced a demand effect and produced "unusual" recollections. To counter this potential, we instructed the participants that their responses should be based on their audit experience during the past three years, and emphasized that there were no "right" or "wrong" answers to any of the questions.

Secondly, respondents might have been prompted by our query to ascribe greater importance to factors in retrospect than they actually had at the time. Respondents also may be biased by the recalled outcomes of situations or by feelings of accountability

\footnotetext{
${ }^{5}$ One of the researchers and a trained research assistant jointly conducted all of the interviews using a prepared script. Each interview took one hour, on average. All participants consented to having their interviews audio-taped, subject to our guarantee of confidentiality.
} 
to the researchers, prompting efforts at "helpfulness". Three actions were taken to minimize this possibility. First, the questionnaire provided minimal guidance on what a particular knowledge-sharing situation might be like, and asked respondents to use their own words (later coded to categories not known to the respondents). Secondly, questions were simple and action-oriented to avoid retrospection. Thirdly, we asked no questions about the psychology of knowledge sharing to avoid contaminating the straightforward recall we sought or biasing responses toward our categories.

Finally, to ensure consistent interpretation of terms and questions, we asked participants to examine a schematic description of knowledge flows in the three audit stages before answering the questions. This schema describes data collection and decision-making responsibilities by rank, and the primary communication mode involved in each process (i.e. written vs verbal). It was developed using a multi-stage process of consultation with experienced auditors. ${ }^{6}$

\subsection{Participants}

The participants are auditors from two Big Four firms in the US. Based on Kinney (1986) and Cushing and Loebbecke (1986), the audit approach of one of our sample firms is classified as being highly structured, while the other is classified as having a low-structure audit approach. ${ }^{7}$ The firms' participation was predicated on anonymity, and they are identified hereafter as high-structure and low-structure. We interviewed eight auditors from the low-structure firm, and nine from the high-structure firm, ranging from staff associate to partner. We also sent 45 copies of the instrument for distribution within the two offices. 16 (out of 25) completed questionnaires were received from the low-structure firm, and 15 (out of 20) from the high-structure firm. ${ }^{8}$ Thus, our combined sample from the interviews and survey consists of 24 auditors from each firm. Since a one-way analysis of variance did not find any significant differences in the numerical

\footnotetext{
${ }^{6} \mathrm{~A}$ copy of this schema is available from the second author on request.

${ }^{7}$ With the recent trend towards CPA firm mergers and more holistic audit approaches, some may question whether there still are distinguishing differences across accounting firms' audit structures. The most recent evidence on this issue that we can find is reported by Prawitt (1995), who performed a structure evaluation of the (then) Big Six firms and found that prior firm-level structure categorizations still applied. In addition, Prawitt (1995) had independent raters evaluate the level of structure of 19 specific audit tasks, including aggregating and evaluating the results of substantive testing. These two evaluation tasks received ratings parallel to the overall firm-level structure. Highly structured firms had more structured approaches for aggregation and evaluation of substantive testing results than did less structured firms. However, since Prawitt's (1995) study is now over 10 years old, we cannot rule out the possibility that there has been a convergence in CPA firms' audit structures in the interim. Whether this is so is an open empirical question. The offices of the two firms from which the participants are drawn are comparable in total number of employees. One has 400 employees, and the other has 420 employees. The two offices' client compositions are also similar, with the majority being Fortune 500 companies and medium-size companies.

${ }^{8}$ The number of surveys distributed in each firm was based on negotiations with its contact person, who agreed to distribute the surveys about equally among partners, managers, seniors and staff. It was infeasible to compare early and late responses as a check for non-response bias. This is because the participants in each firm had returned their sealed and anonymous responses to the contact person in their firm, who then transmitted them to us in a set. However, the rather high response rate provides some assurance that any non-response bias would be limited.
} 
responses of the interview versus survey participants, data from the two groups were combined for analysis.

\section{Findings}

\subsection{Descriptive Statistics}

The participants average 7.77 years of auditing experience (ranging from 1 to 30 years), have conducted an average of over 30 audits in the past three years, and have worked on an average of 25 audit teams over the same period. One-way analyses of variance show that none of the experience-related measures is significantly different between participants from the two firms $(p>0.65)$. On average, participants rate knowledge sharing in the fieldwork stage as being significantly more important than that in the planning and opinion formulation stages (all $p$-values $\leq 0.02$ ). They also have similar mean ratings for workload (81.88 and 84.83) and closeness of supervision (69.88 and 70.92). As for knowledge sharing, respondents from both firms indicate that they have experienced rather high overall levels of openness (86.46 and 80.54, respectively). However, both levels are still short of being totally open and complete, with that in the low-structure firm being significantly higher than in the high-structure firm $(t=1.678, p$ $=0.05$; two-tailed). Across the three audit stages, knowledge sharing is rated to be least open in the planning stage. Also, openness of knowledge sharing is positively related to the closeness of supervision ( $t=2.411, p=0.01$, two-tailed). ${ }^{9}$

\subsection{Analysis}

First, we performed a limited-scale test of our literature-based inferences by regressing overall knowledge sharing openness on one factor each from the firm level (structure of the audit approach, high $=1$, low $=0$ ), the audit team level (closeness of supervision, 0 (low) to 100 (high)) and the individual auditor level (rank, $1=$ staff, $2=$ senior, 3 = manager, 4 = partner). Structure had a negative and marginally significant coefficient ( $p=0.10$, two-tailed), while the coefficients for level of supervision and rank were both positive and significant at conventional levels. ${ }^{10}$ These results suggest that overall, openness of knowledge sharing is lower in the high-structure firm than in the low-structure firm, closeness of supervision enhances openness of knowledge sharing in audits, and knowledge sharing is seen as being more open at higher ranks. ${ }^{11}$ Perhaps

\footnotetext{
${ }^{9}$ Detailed descriptive statistics are available from the second author on request.

${ }^{10}$ We obtained the same pattern of results using dummy variables for coding the positions of staff (used as the baseline), senior, manager and partner. In that regression, the coefficients for manager and partner were both positive and significant, while the coefficient for seniors was not. Further, replacing the rank variable with each participant's audit experience in months (which is, as might be expected, highly and positively related to rank) yielded a significant and positive coefficient for this variable without affecting the pattern of significant coefficients for the other variables.

${ }^{11}$ We also ran a regression that included the interaction between audit structure and rank. The coefficient for this interaction term was not statistically significant $(p>0.50)$.
} 
more important, they provide some measure of comfort that our approach of making inferences from the literature is not an unreasonable one.

Separate regressions for the planning, fieldwork and reporting stages show that auditors' openness in sharing information is affected by the closeness of supervision (coefficient is $0.387 ; t=2.578 ; p=0.015$ ) in the planning stage and by rank (coefficient is $5.931 ; t=2.834 ; p=0.007$ ) in the reporting stage; none of the factors is significant in the fieldwork stage. This suggests that knowledge sharing is subject to different influences in different audit stages.

To gain insights from the open-ended responses, one of the authors first generated a list of summary phrases for capturing commonalities in the responses. Then a research assistant with extensive audit experience independently evaluated these against the responses for consistency, clarity, and completeness, and a small number of modifications were made to arrive at a consensus list. The research assistant then used this list to prepare a frequency count, which was independently verified by the same author. While this process cannot fully guarantee against subjective biases or interpretation errors, we feel confident that the thrust of the responses has been preserved.

In total, the participants identified 17 impediments to knowledge sharing in an audit engagement. Table 1 shows these factors as well as the number of participants from each firm who mentioned a given barrier in each audit stage. Since some participants considered a given factor to be a barrier for only one audit stage while others saw it as being operant in multiple stages, the last column of the table also reports the total number of different participants who mentioned each barrier. 


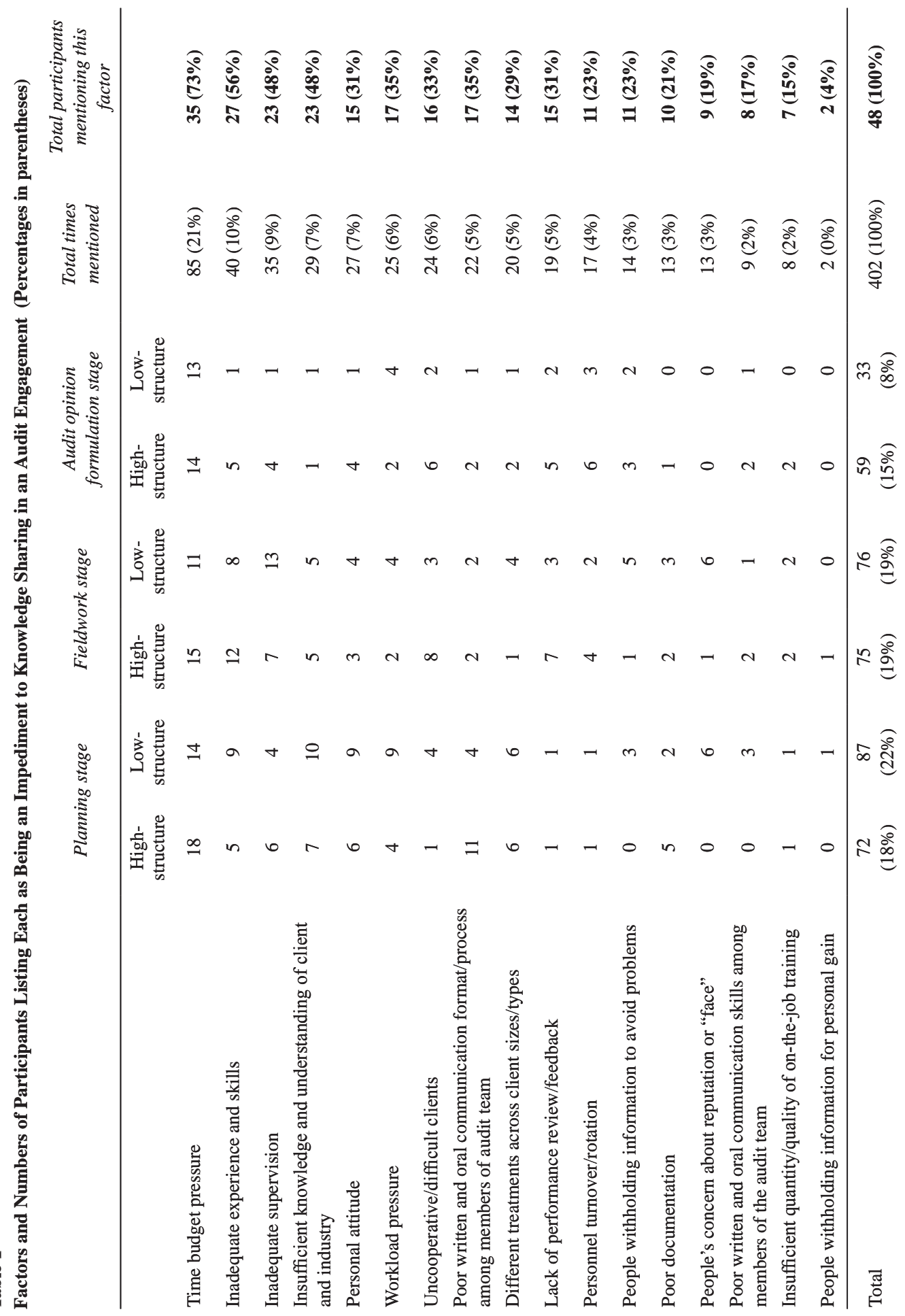


Table 1 shows that the 17 impediments were mentioned a total of 402 times by the participants across the three audit stages. The rather high average number of mentions (8.375) per participant suggests that the auditors were engaged by the study. This statistic also indicates that barriers to knowledge sharing are not a rare phenomenon. There are some discernible differences between the low- and high-structure firms in the distribution of each impediment's number of mentions in each stage. However, the small sample sizes at such a disaggregated level preclude statistical tests for significant differences. Thus, for parsimony, we will focus on the overall pattern rather than on each audit stage.

Both time budget pressure and workload pressure can be considered manifestations of a tight work schedule. The former is mentioned by the largest number of participants (35, or $73 \%$ of the sample) and with the highest frequency (85 times). Workload pressure is the fifth most often cited barrier in terms of participants (17) and is mentioned a total of 25 times. Inadequate supervision is mentioned 35 times by 23 different participants, or $48 \%$ of the sample. This last finding can be viewed as validation for the quantitative result, reported earlier, that a positive relation exists between the closeness of supervision and openness of knowledge sharing.

The participants' open-ended comments shed further light on the nature of each impediment and how it reduces knowledge sharing in an audit. ${ }^{12}$ In discussing the effects of time budget pressure, they commonly mentioned the desire to "get done". The comments on workload pointed to people only reacting to problems, lack of coordination among team members (so that different members may be working from different drafts of the same report) and the difficulty of shifting time and attention among multiple audits. The comments on inadequate supervision further suggest that some barriers are interrelated. For example, participants pointed to audit staff not getting enough instruction due to time and workload pressure ("People are over-extended and stressed out... they prioritize their own jobs, and don't have time to talk to the people below them") and higher-ranked members of the audit team only reviewing "high spots”.

Other highly-cited obstacles include inadequate experience and skills, and insufficient knowledge and understanding of the client and its industry. These are, respectively, the second and fourth most-often mentioned (40 and 29 mentions by 27 and 23 participants, respectively). Both factors have to do with characteristics of individual audit team members. The nature of the latter barrier is self-evident, while comments relating to the former point to staff not being able to critically evaluate audit findings and information provided by clients, so they do not mention this to others (e.g. "The staff take everything the client says as gospel. They might not realize that there is something wrong so they do not think it is important enough to mention”). This barrier is seen to apply to more senior personnel as well, such as new managers not knowing how much detail to give to the senior. Other barriers that also relate to individual characteristics include personal attitude (e.g. "Some seniors are not approachable, and the audit staff do not feel comfortable asking them questions"), concern for reputation or "face", (e.g. "Sometimes people are not sure what it is they need to do, but they do

\footnotetext{
${ }^{12}$ A detailed table of such quotes is available from the second author on request.
} 
not want to give anyone the impression that they do not know”), lack of written and oral communication skills and a tendency to withhold information to avoid problems or for personal gain (e.g. "There is a feeling that knowledge is power; whenever there is something someone perceives he/she could become an expert in, he/she becomes the owner of that piece of information").

The remaining barriers span factors at the levels of the audit team, audit firm, and beyond. Factors at the audit team level include lack of a standard communication format/ process among audit team members, poor documentation, and higher-ranked team members not providing sufficient quantity/quality of on-the-job training to those at lower levels. Again, the comments show interrelations among the barriers. For example, time pressure was noted as an important reason why higher-ranked team members do not devote more time to coaching: "They (the firm) put such strict budgets on jobs that the senior doesn't have time to sit down and say, 'This is what we do and this is how it fits in'. And if they do that, it looks bad for them because they run over the budget".

Among the obstacles that pertain to the audit firm level are differential emphasis on planning contingent on client type/size, and personnel turnover/rotation. Again, comments relating to these factors suggest that different barriers are interrelated. For example, rotation of personnel across audits is identified as a reason why more time is not devoted to on-the-job training or coaching ("You are forming and disbanding a lot of teams, and in some cases it is not efficient to coach because you are not necessarily going to work with them again; they are going to be working with someone else"). Finally, a barrier that goes beyond the audit firm is the audit client. 16 (33\%) participants mentioned uncooperative/difficult clients a total of 24 times as a barrier to knowledge sharing. Many of the comments relate to the difficulty of obtaining cooperation and information from clients. Undoubtedly, this factor adds to the workload/time pressure and the tendency to avoid surfacing problems ("The clients...get upset if you start calling them two weeks after you're out of fieldwork"). The comments also suggest that client-related barriers vary across client types ("Hiding information depends on the client, and it happens more with private clients than with public clients").

As reported earlier, we also asked participants to suggest actions that their firms could take to increase the openness of knowledge sharing in an audit. As might be expected, there was substantial overlap between the suggested actions and the barriers. Thus, for parsimony, we will only discuss the highlights. ${ }^{13}$ First, the suggested actions encompass the full range of factors, from the audit client ("Improve working relations with clients") to policies and processes at the audit firm level (e.g. "Improve hiring/ retention policies and procedures"; "Requiring planning and planning meetings"; "Increase attention to performance reviews"), to factors relating to the audit team, engagement and individual auditors (e.g. "Improve supervision and quantity/quality of on-the-job training"; "Involve more audit engagement team members in the meetings"). Also of interest is that there was a shared sentiment that higher level personnel should lead by example ("I think the best thing the firm can do is that the people at the top set the example"; "When you see the partners and managers take more of an interest on the front end of engagements, by default your seniors and staff are going to be encouraged

\footnotetext{
${ }^{13}$ Detailed tables are available from the second author on request.
} 
by that"). In sum, the auditors' responses to the interview and survey questions about barriers and remedial measures paint a consistent picture and suggest a rich set of factors and interrelationships that can affect knowledge sharing in an audit.

\section{Summary and Discussion}

Figure 1 presents a framework for organizing the multitude of factors and relationships suggested by the participants and the related literature. Beyond containing a large number of factors, an important feature of this framework is that it suggests a rich web of interrelationships among factors at each level as well as across levels. For example, the participants' responses suggest that a high level of personnel turnover/ rotation can affect both the experience of audit team members and the motivation for higher-ranked audit team members to coach their junior colleagues. Specific attributes of the client (size, public vs private) are seen as affecting the emphasis placed on planning, as well as higher-ranked audit team members' tendency to withhold from subordinates unfavorable knowledge about the client. 
Figure 1

A Framework for Organizing the Factors Affecting Knowledge Sharing in Audit Engagements

\section{Audit firm level factors:}

Firm culture

Structure of audit approach

Performance evaluation/ reward system

Personnel selection

Personnel turnover

Use of information technology

Size of office

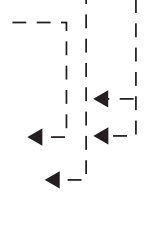

Audit team level factors:

Closeness of supervision ------- ,

Workload pressure $---------1--$ ᄀ

Time budget pressure - - - - - -

Communication format/process -

Auditor rotation - - - - ,

On-the-job training

Time spent in planning

Documentation

Procedural justice and trust

Role conflict/ambiguity

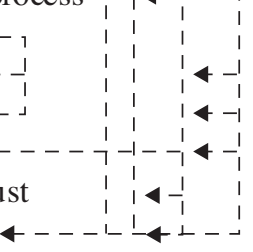

$$
1
$$

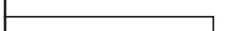


Despite the complexity of this figure, it is only a start in capturing the richness of the phenomenon. In addition to increasing the sample sizes both in terms of audit firms and auditors, future research could further disaggregate the relevant variables. For example, there is room for investigating what are the key aspects, or components, of audit approach structure and performance evaluation processes that affect the propensity for knowledge sharing, as well as the channels and processes involved in the sharing. There also is room to recognize that the literature has identified two types of knowledge-explicit and tacit. Explicit knowledge, or "know-what", can be captured, codified, categorized, and stored, and is easy to transmit in a formal language (Bartol and Srivastava, 2002; Stenmark, 2000). Tacit knowledge, or "know-how", is embodied in the habitual practices and mental models of individuals (Lakoff and Johnson, 1999; Polanyi, 1997). As such, tacit knowledge is not easily articulated because it is subconsciously understood and applied, and it resides in people's minds as intuitions, insights, beliefs, or values (Ambrosini and Bowman, 2001; Ancori et al., 2000). We had excluded this distinction from our study to reduce "noise" due to respondents making different assignments between the two knowledge categories. However, future research could examine, for example, the mix of explicit and tacit knowledge that is transferred in audit firms, the factors that affect the openness with which each type of knowledge is shared, the channels and processes involved in the sharing, and the relative impacts of sharing the two types of knowledge on the efficiency, effectiveness and integrity of the audit process.

It also would be worthwhile to further explore the interactions among factors. In our regression analysis, we only included one factor each from the firm, team and individual levels. There is much room for future research to examine multiple factors within each level as well as the interactions within and between different levels. For example, both the professional and academic accounting literatures provide evidence that audit firms with highly structured audit technologies allow relatively complex knowledge to be applied by less experienced auditors (Prawitt, 1995). Thus, less experienced auditors in highly structured firms may feel less need for, or are more reluctant to seek, guidance from their supervisors, choosing instead to rely on the knowledge contained in the databases or in clients' working papers. In contrast, less experienced auditors in lowstructure firms may see their superiors as being more willing to provide guidance because they have fewer firm-supplied decision aids and databases for support. Similarly, audit teams' attention to planning may be affected by how much their firms emphasize this activity in performance evaluation. More broadly, in addition to interpersonal exchanges, knowledge transfers can occur through a variety of mechanisms. Examples include personnel movement (Gruenfeld et al., 2000), observation (Nonaka, 1991), alliances and other forms of inter-organizational relationships (McEvily and Zaheer, 1999). Future research can benefit from expanding the sphere of consideration to these other avenues of knowledge sharing. Also, we had assumed that increased openness of knowledge sharing enhances audit efficiency and effectiveness. While this would seem like a reasonable assumption, research is needed to evaluate both its efficacy in general, and the processes and pathways whereby such effects occur. In conducting such inquiries, there is room for going beyond perception data obtained from interviews and surveys to seek information via direct observations and experiments. 
Finally, it is worth noting that this study has only explored auditors' knowledge sharing in the U.S. context. Prior studies have documented that people in different countries have different culture-related traits (Chow et al., 1999a; Hofstede, 1991). For example, Chinese nationals' concern for "face" (Triandis, 1989; Chow et al., 1999b) may prevent subordinates from requesting help from their peers or superiors for fear that doing so may make them look less knowledgeable and more dependent on others to do their job. Furthermore, the mix of audit challenges also may differ across nations due to institutional differences (Chow et al., 2006). Given the increasing globalization of audit firms and engagements, future studies can explore cross-national differences in knowledge sharing challenges, as well as their facilitators and barriers.

\section{References}

Abdolmohammadi, M. and J. Shanteau, 1992, "Personal Attributes of Expert Auditors”, Organizational Behavior and Human Decision Processes 53, 158-172.

Ambrosini, V. and C. Bowman, 2001, "Tacit Knowledge: Some Suggestions for Operationalization”, Journal of Management Studies 38, 811-829.

Ancori, B., A. Bureth, and P. Cohendet, 2000, "The Economics of Knowledge: The Debate about Codification and Tacit Knowledge”, Industrial and Corporate Change 9, 255-287.

Bamber, E.M., L.S. Bamber and R. Tubbs, 1989, “Audit Structure and its Relation to Role Conflict and Role Ambiguity: An Empirical Investigation", The Accounting Review 64, 285-299.

Bamber, E.M. and V.M. Iyer, 2002, “Big 5 Auditors' Professional and Organizational Identification: Consistency or Conflict?", Auditing: A Journal of Practice and Theory 12 (September), 21-38.

Banker, R., H. Chang and Y.C. Kao, 2002, "Impact of Information Technology on Public Accounting Firm Productivity”, Journal of Information Systems (Fall), 209-222.

Bartol, K. and A. Srivastava, 2002, "Encouraging Knowledge Sharing: The Role of Organizational Reward Systems", Journal of Leadership and Organizational Studies 9, 64-76.

Bell, T., M. Peecher and I. Solomon, 2005, The 21 st Century Public Company AuditConceptual Elements of KPMG's Global Audit Methodology (KPMG: Montvale, $\mathrm{NJ})$.

Bhimani, A., 2003, "A Study of the Emergence of Management Accounting System Ethos and its Influence on Perceived System Success", Accounting, Organizations and Society 28, 523-548.

Bierstaker, J. and A. Wright, 2001, “The Effects of Fee Pressure and Partner Pressure on Audit Planning Decisions", Advances in Accounting 18, 25-46.

Bonner, S. and P. Walker, 1994, "The Effects of Instruction and Experience on the Acquisition of Auditing Knowledge”, The Accounting Review 69 (January), 157178.

Bowrin, A., 1998, "Review and Synthesis of Audit Structure Literature”, Journal of Accounting Literature 17, 40-71. 
Brazel, J.F., C.P. Agoglia and R.C. Hatfield, 2004, "Electronic versus Face-to-face Review: The Effects of Alternative Forms of Review on Auditors' Performance", The Accounting Review 79, 949-966.

Carpenter, B.W., M.W. Dirsmith and P.P. Gupta, 1994, "Materiality Judgments and Audit Firm Culture: Social-behavioral and Political Perspectives", Accounting, Organizations and Society 19, 355-380.

Chow, C., J.C. Cooper and K. Haddad, 1991, "The Effects of Pay Schemes and Ratchets on Budgetary Slack and Performance: A Multi-period Experiment”, Accounting, Organizations and Society 16, 47-60.

Chow, C., M. Shields and A. Wu, 1999a, "The Importance of National Culture in the Design of Management Controls for Multi-national Operations”, Accounting, Organizations and Society 24, 441-461.

Chow, C., G. Harrison, J. McKinnon and A. Wu, 1999b, "Cultural Influences on Information Sharing in Chinese and Anglo-American Organizations: An Exploratory Study”, Accounting, Organizations and Society 24, 561-582.

Chow, C., J. Deng and J. Ho, 2000, "The Openness of Knowledge Sharing within Organizations: A Comparative Study of the United States and the People's Republic of China”, Journal of Management Accounting Research 12, 65-95.

Chow, C., G. Harrison, J. McKinnon and A. Wu, 2002, "The Nature and Effects of Public Accounting Firm Organizational Culture: Evidence from Taiwanese Local and U.S. Affiliated Firms", Accounting, Organizations and Society 27 (4/5), 347360.

Chow, C., J. Ho and P. Mo, 2006, “Towards Understanding Chinese Auditors' Structuring of Audit Approaches, Client Acceptance Decisions, Risk Assessment, and Stringency of Imposed Reporting Standards”, Journal of International Accounting Research 5 (1), 1-23.

Collins, C.J. and K.G. Smith, 2006, "Knowledge Exchange and Combination: The Role of Human Resource Practices in the Performance of High-technology Firms", Academy of Management Journal 49, 544-560.

Cushing, B. and J. Loebbecke, 1986, Comparison of Audit Methodologies of Large Accounting Firms, Accounting Research Study No. 26 (American Accounting Association: Sarasota, FL).

Cyert, R. and J. March, 1992, A Behavioral Theory of the Firm ( $2^{\text {nd }}$ edition) (Blackwell: Oxford, UK).

Fisher, J.G., L.A. Maines, S.A. Peffer and G.B. Sprinkle, 2005, “An Experimental Investigation of Employer Discretion in Employee Performance Evaluation and Compensation”, The Accounting Review 80 (2), 563-583.

Francis, J., 1994, "Auditing, Hermeneutics, and Subjectivity", Accounting, Organizations and Society 19, 235-269.

Geiger, M. and K. Raghunandan, 2002, "Auditor Tenure and Audit Reporting Failures”, Auditing: A Jounal of Practice \& Theory 21, 67-78.

Gramling, A., 1999, “External Auditors' Reliance on Work Performed by Internal Auditors: The Influence of Fee Pressure on this Reliance Decision", Auditing: A Journal of Practice \& Theory 18 (Supplement), 117-135. 
Gregson, T., J. Wendell and J. Aono, 1994, “Role Ambiguity, Role Conflict, and Perceived Environmental Uncertainty: Are the Scales Measuring Separate Constructs for Accountants?” Behavioral Research in Accounting 6, 144-159.

Gruenfeld, D., P. Martorana and E. Fan, 2000, "What Do Groups Learn from Their Worldliest Members? Direct and Indirect Influence in Dynamic Teams”, Organizational Behavior and Human Decision Processes 82, 45-59.

Hall, R., 1996, Organizations: Structures, Processes, and Outcomes (Prentice-Hall: Englewood Cliffs, NJ).

Harding, N. and K. Trotman, 1999, "Hierarchical Differences in Audit Workpaper Review Performance”, Contemporary Accounting Research 16, 671-684.

Henri, J., 2006, “Organizational Culture and Performance Measurement Systems”, Accounting, Organizations and Society 31, 77-103.

Hickins, M., 1999, “Xerox Shares its Knowledge”, Management Review (September), 40-45.

Hofstede, G.H., 1991, Cultures and Organizations: Software of the Mind (McGraw-Hill: Berkshire, UK).

Hyatt, T. and D. Prawitt, 2001, "Does Congruence between Audit Structure and Auditors’ Locus of Control Affect Job Performance?”, The Accounting Review 76 (2), 263-274.

Ketchand, A. and J. Strawser, 2001, “Multiple Dimensions of Organizational Commitment: Implications for Future Accounting Research”, Behavioral Research in Accounting 13, 221-252.

Kinney, W., 1986, “Audit Technology and Preferences for Auditing Standards”, Journal of Accounting and Economics 8, 73-89.

Knechel, W.R., 2000, "Behavioral Research in Auditing and its Impact on Audit Education”, Issues in Accounting Education 15 (November), 695-712.

KPMG, 2000, Knowledge Management Research Report (KPMG Management Consulting: New York, NY).

Lakoff, G. and M. Johnson, 1999, Philosophy in the Flesh: The Embodied Mind and its Challenge to Western Thought (Basic Books: New York).

McEvily, B. and A. Zaheer, 1999, "Bridging Ties: A Source of Firm Heterogeneity in Competitive Capabilities”, Strategic Management Journal 20, 1133-1156.

McNair, C., 1991, “Toward Value-added Management Accounting”, CIMA Magazine 65, 26-28.

Matsumura, E.M. and J.Y. Shin, 2006, “An Empirical Analysis of an Incentive Plan with Relative Performance Measures: Evidence from a Postal Service”, The Accounting Review 81 (3), 533-566.

Murthy, U. and D. Kerr, 2004, “Comparing Audit Team Effectiveness via Alternative Modes of Computer-mediated Communication”, Auditing: A Journal of Practice \& Theory (March), 141-152.

Nonaka, I., 1991, “The Knowledge-creating Company”, Harvard Business Review 69, 96-104.

Polanyi, M., 1997, “Tacit Knowledge”, in L. Prusak (ed.), Knowledge in Organizations (Butterworth-Heinemann: Boston), 99-134. 
Prawitt, D.F., 1995, "Staff Assignment for Judgment-oriented Audit Tasks: The Effects of Structured Audit Technology and Environment”, The Accounting Review 70 (3), 443-465.

Public Oversight Board (POB), 1994, Strengthening the Professionalism of the Independent Auditor, (September 13), (POB: Stamford, CT).

Putti, J., S. Aryee and J. Phua, 1990, “Communication Relationship Satisfaction and Organizational Commitment”, Group and Organization Studies 15, 44-52.

Raghunathan, B., 1991, "Premature Signing-off of Audit Procedures: An Analysis", Accounting Horizons (June), 71-79.

Ramsay, R., 1994, "Senior/manager Differences in Audit Workpaper Review Performance”, Journal of Accounting Research 32 (Spring), 127-135.

Robinson, H.S., C.J. Anumba, P.M. Carrillo and A.M. Al-Ghassani, 2006, "STEPS: A Knowledge Management Maturity Roadmap for Corporate Sustainability”, Harvard Business Review 12 (6), 793-808.

Rudolph, H. and R. Welker, 1998, “The Effects of Organizational Structure on Communication within Audit Teams”, Auditing: A Journal of Practice \& Theory 17 (2), 1-14.

Special Report, 2005, “Auditing Sarbanes-Oxley-A Price Worth Paying?” The Economist (May), 71-73.

Stenmark, D., 2000, “Leveraging Tacit Organizational Knowledge”, Journal of Management Information Systems 17 (Winter), 9-24.

Stimpson, J., 1999, “In the Know”, Practical Accountant 32 (June), 34-39.

Tan, H.T. and R. Libby, 1997, “Tacit Managerial versus Technical Knowledge as Determinants of Audit Expertise in the Field”, Journal of Accounting Research 35 (Spring), 97-113.

The Controller's Report, 2005, "Staying Current-New FEI Study: 39\% Rise in SOX Compliance Cost”, (May), available at www.ioma.com.

Triandis, H.C., 1989, “The Self and Social Behavior in Differing Culture Contexts”, Psychological Review 96 (July), 506-520.

Umemoto, K., A. Endo and M. Machado, 2004, "From Sashimi to Zen-in: The Evolution of Concurrent Engineering at Fuji Xerox”, Journal of Knowledge Management 8, 89-92.

Vera-Muñoz, S., J. Ho and C. Chow, 2006, "Enhancing Knowledge Sharing in Accounting Firms”, Accounting Horizons 20 (2), 133-155.

Weick, K., 2005, “Managing the Future: Foresight in the Knowledge Economy”, Academy of Management Review 30 (4), 871-873.

Windsor, C.A. and N.M. Ashkanasy, 1996, “Auditor Independence Decision Making: The Role of Organizational Culture Perceptions”, Behavioral Research in Accounting 8, 80-97.

Winograd, B., J. Gerson and B. Berlin, 2000, "Audit Practices of PricewaterhouseCoopers”, Auditing: A Journal of Practice \& Theory (Fall), 175182. 